\title{
Analisis Break Even Point (BEP) Usahatani Pembibitan Sapi Potong di Kabupaten Sleman
}

\author{
S. Emawati \\ Jurusan Peternakan, Fakultas Pertanian, Universitas Sebelas Maret \\ Jl. Ir. Sutami 36 A, Kentingan, Surakarta \\ Email: emawati.shanti@gmail.com
}

\section{INTISARI}

Penelitian ini bertujuan untuk menentukan break even point (BEP) pada usahatani pembibitan sapi potong. Penelitian dilaksanakan mulai bulan Januari sampai dengan Mei 2007 dengan lokasi di Kabupaten Sleman. Metode penelitian yang digunakan adalah survei untuk mengumpulkan data primer dari responden dan data sekunder dari dinas terkait. Responden diambil secara purposive sampling. Nilai BEP dengan penghitungan penjualan pedet berdasarkan kondisi peternak pada sapi Peranakan Simmental, PO dan Peranakan Limousine berturut-turut sebesar 8, 9 dan 7 ekor induk.

Kata kunci : pembibitan sapi potong, analisis BEP

\section{Break Even Point Analysis of Cattle Breeding Farm in Sleman District}

\section{ABSTRACT}

The research was conducted to calculate the break even point (BEP) of cattle breeding farm. Research was done from January to May 2007, located in Sleman District. Survey methods was done to collect primary data at the farm level and secondary data from related institution. Purposive sampling was applied to sellect farmers' respondent. The BEP with calf sales calculation of keeping Simmental, Ongole and Limousine grade cattle were 8, 9 and 7 cows per farmer respectively, which mean that farmers will annually benefited from keeping cattle when the number of cows was larger than those of BEP.

Key words : cattle breeding farm, BEP analysis

\section{PENDAHULUAN}

Komoditas ternak sapi potong memiliki prospek cerah bagi peternakan Indonesia, terlihat konsumsi daging sapi dalam lima tahun terakhir cenderung mengalami peningkatan rata-rata per tahun sebesar 11,07\%. Tahun 2001 konsumsi daging sapi sebesar 355.041,5 ton, kemudian tahun 2006 mengalami kenaikan menjadi sebesar 380.086,5 ton. Meningkatnya permintaan daging sapi yang belum diimbangi dengan peningkatan populasi akan menyebabkan pengurasan sapi potong terutama sapi bakalan dan pemotongan sapi betina produktif Secara keseluruhan populasi sapi potong di Indonesia pada lima tahun terakhir, menurun rata-rata $0,49 \%$ per tahun. Pada tahun 2001, populasi sapi potong sebesar 11.137.701 ekor, kemudian tahun 2006 mengalami penurunan menjadi sebesar 10.835.686 ekor (Ditjen Peternakan, 2006). 
Permasalahan yang dihadapi dalam usaha sapi potong di Indonesia adalah lebih dari $90 \%$ dipelihara oleh petani dengan cara tradisional, skala usaha kecil, usaha sambilan dan teknologi masih sederhana sehingga produktivitasnya rendah. Kemampuan peternak kita dalam memproduksi ternak khususnya untuk bibit masih sangat terbatas karena pada usaha pembibitan sapi potong membutuhkan investasi yang cukup besar bila diukur oleh kemampuan peternak kecil dalam menyediakan modal. Demikian juga jangka waktu menghasilkan cukup lama, membutuhkan luangan waktu untuk memelihara yang relatif panjang. Meskipun demikian secara ekonomi modal atau investasi tidak menjadi masalah apabila suatu usaha profitable atau layak untuk diusahakan. Salah satu parameter indikator kelayakan tersebut adalah break even point (BEP).

Break even merupakan suatu keadaan dimana seluruh penerimaan hanya mampu menutup seluruh pengeluaran. Analisis BEP adalah suatu cara yang digunakan oleh seorang pengambil keputusan proyek finansial untuk mengetahui kondisi batas pada kuantitas produksi/penjualan biaya berapa usahatani tersebut mengalami keuntungan dan menderita kerugian (Pasaribu, 2005). Oleh karena itu, penulis tertarik untuk mengadakan penelitian tentang analisis BEP pada usahatani pembibitan sapi potong. Tujuan dari penelitian adalah untuk menentukan break event point (BEP) pada usahatani pembibitan sapi potong.

\section{MATERI DAN METODE}

Penelitian dilaksanakan pada bulan Januari sampai dengan Mei 2007 berlokasi di Kabupaten Sleman. Materi yang digunakan dalam penelitian adalah peternak pembibitan sapi potong di Kabupen Sleman, ternak sapi dan kuesioner.

\section{Penentuan Lokasi}

Metode penentuan lokasi penelitian ditentukan secara sengaja, dengan lokasi contoh penelitian di Kabupaten Sleman dengan pertimbangan bahwa di lokasi tersebut terdapat beberapa Kelompok Tani Ternak (KTT) yang selanjutnya diambil sebagai sampel penelitian. Lebih rincinya dapat dilihat pada Tabel 1.

Tabel 1. Nama dan Alamat Kelompok Tani Ternak

\begin{tabular}{clllc}
\hline \hline N. & Nama Kelompok Tani Ternak & \multicolumn{1}{c}{ Desa } & Kecamatan & Jumlah \\
\hline 1 & Sedyo Raharjo, Andini Harjo & Caturharjo & Sleman & 16 orang \\
2 & $\begin{array}{l}\text { Andini Gotro, Sido Maju, } \\
\text { Andini Jaya }\end{array}$ & Tambakrejo & Tempel & 20 orang \\
3 & Sido Rukun, Tlogowono & Jogotirto & Berbah & 12 orang \\
4 & Marangan, Gangsiran & $\begin{array}{l}\text { Bokoharjo, } \\
\text { Madurejo }\end{array}$ & Prambanan & 12 orang \\
\hline
\end{tabular}

Sumber : Data primer terolah, 2007

\section{Pengambilan Sampel Peternak}

Metode pengambilan sampel peternak dengan purposive sampling yaitu dipilih peternak dikelompok sampel yang telah memelihara induk sapi potong minimal 1 tahun dan pernah beranak. Jumlah sampel yang diambil dalam penelitian adalah 60 responden dengan pengambilan secara proporsional pada setiap kelompok.
Pemilihan secara purposive berarti sampel dipilih dan ditetapkan berdasarkan atas pertimbangan-pertimbangan tertentu yang sesuai dengan tujuan penelitian (Sugiyono, 2006).

\section{Pengambilan Data}

Pengambilan data dilaksanakan dengan metode survey. Data yang diambil 
adalah data primer dan data sekunder. Data primer diperoleh dari wawancara kepada responden peternak sapi potong dengan menggunakan kuesioner. Data sekunder untuk menunjang data primer diperoleh dari Dinas Pertanian dan Kelautan, Sub Dinas Peternakan Sleman.

\section{ANALISIS DATA}

\section{Koefisien Teknis}

Koefisien teknis yang berpengaruh pada biaya dan penerimaan usaha pembibitan sapi potong yaitu calving interval, service per conception, mortalitas dan umur penjualan pedet.

\section{Analisis Biaya dan Penerimaan}

Biaya yang diperlukan dalam analisis ini adalah biaya investasi dan biaya operasional. Penerimaan diperoleh dari penjualan pedet sebagai produk pokok dan penjualan kotoran sebagai produk sampingan.

\section{Analisis Cash Flow}

Analisis cash flow yang digunakan dalam analisis ini adalah memperhitungkan nilai output input sesuai dengan koefisien teknis dari pemeliharaan 2 ekor sapi induk berdasarkan umur investasi 7 tahun dengan discount factor $12 \%$ per tahun.

\section{Analisis Break Even Point (BEP)}

Variabel yang diperlukan dalam analisis BEP adalah biaya tetap, biaya tidak tetap dan penjualan anak sapi. Rumus yang digunakan adalah :

$$
\text { Penjualan BEP }=\frac{\text { Biaya tetap }}{1-\frac{\text { Biaya variabel }}{\text { Penjualan }}}
$$

$$
\text { BEP dalam unit }=\frac{\text { Penjualan BEP }}{\text { Harga jual per unit }}
$$

*) Unit dalam usahatani pembibitan sapi potong adalah ekor induk.

\section{Batasan Operasional}

Peternak yang diambil sebagai sampel dalam penelitian adalah peternak yang mengusahakan pembibitan sapi potong dengan memiliki induk yang telah beranak minimal 1 ekor dan telah dipelihara minimal 1 tahun. Perhitungan berdasarkan umur investasi 7 tahun dengan discount factor $12 \%$ per tahun sesuai dengan tingkat bunga yang berlaku pada usahatani ternak tersebut. Perhitungan produksi meliputi produk pokok berupa penjualan pedet dan produk sampingan berupa penjualan kotoran. Opportunity cost tenaga kerja yang tidak dibeli.

\section{HASIL DAN PEMBAHASAN}

\section{Identitas Peternak}

\section{Umur peternak}

Umur peternak sapi potong di lokasi penelitian berkisar antara 25 sampai 80 tahun dengan rata-rata 50 tahun. Umur peternak digolongkan menjadi 3 kelompok yaitu petani taruna yang berusia antara $15-$ 25 tahun, petani muda yang berusia antara 25 - 44 tahun dan petani dewasa yang berusia diatas 45 tahun (Soegiharto, 2004). Berdasarkan penelitian bahwa 66,33\% peternak berusia di atas 45 tahun. Menurut Soegiharto (2004) bahwa sektor pertanian menunjukkan tren aging agriculture, yaitu suatu kondisi dimana tenaga kerja yang berada di pertanian adalah tenaga kerja berusia lanjut.

\section{Tingkat Pendidikan Peternak}

Hasil penelitian menunjukkan bahwa peternak sebagian besar berpendidikan cukup tinggi karena 55\% sudah mengenyam pendidikan 9 tahun. Tingkat pendidikan peternak tersebut berpengaruh terhadap manajemen peternakan yang dilakukan. Pendidikan peternak menggambarkan kemampuan mengelola ternak sapi. Menurut Mosher (1987), tingkat pendidikan memiliki 
peran penting dalam memahami penggunaan teknologi untuk dapat meningkatkan produktivitas usaha pertanian karena dengan semakin tinggi tingkat pendidikan maka akan lebih mudah memahami dan menerapkan teknologi baru.

\section{Pekerjaan Peternak}

Pekerjaan utama masyarakat sebagian besar adalah petani sebesar 68,33\%. Peternak mengusahakan pembibitan sapi potong hanya sebagai pekerjaan sampingan yang berguna untuk membantu menambah penghasilan keluarga sehingga dapat meningkatkan taraf hidup peternak.

\section{Aspek Teknis Pembibitan Sapi Potong}

\section{Sapi Bibit}

Induk yang dipelihara peternak di lokasi penelitian adalah bangsa sapi Peranakan Simmental (PS) 25 ekor, Peranakan Ongole (PO) 18 ekor, dan Peranakan Limousine (PL) 17 ekor. Alasan peternak memilih bangsa sapi tertentu antara lain : pemeliharaan mudah karena pakan yang dibutuhkan relatif sedikit sehingga selaku tersedia setiap hari; alasan lainnya adalah bangsa sapi yang pertumbuhannya relatif cepat walaupun membutuhkan pakan yang relatif lebih banyak. Sapi induk yang dimiliki oleh responden telah beranak berkisar 2 sampai 7 kali. Dilihat dari harganya, bangsa-bangsa sapi tersebut memiliki nilai tertentu, untuk bangsa PL kisaran harga Rp. 5 juta hingga Rp. 8 juta pada umur antara 2 sampai 9 tahun, untuk bangsa sapi PO kisaran harga Rp. 4,5 juta sampai Rp. 7 juta dengan kisaran umur yang sama dan sapi PS Rp. 5,5 juta sampai Rp. 8 juta.

\section{Pakan, Kandang dan Sewa Lahan}

Secara umum sapi-sapi dipelihara secara intensif yaitu dikandangkan sepanjang hari dengan disediakan pakan yang cukup. Pakan yang diberikan berupa hijauan dan konsentrat. Sebagian besar peternak memelihara ternaknya dengan sistem kandang kelompok yang dibangun dalam suatu lokasi dengan luas kaplingan yang sama. Bagi peternak yang memiliki skala kepemilikan diatas rata-rata maka mereka akan memerlukan lebih dari satu lokal kaplingan. Iuran dan sewa lahan yang ditetapkan masing-masing kelompok berbeda-beda mulai dari Rp. 1.000,00 hingga Rp. 100.000,00 per tahun.

\section{Koefisien teknis}

Koefisien teknis calving interval dan umur penjualan pedet akan berpengaruh pada penerimaan dan biaya produksi. Berdasarkan data primer hasil survei, koefisien teknis disajikan seperti Tabel 2.

Tabel 2. Koefisien Teknis Usaha Pembibitan Sapi Potong di Kabupaten Sleman

\begin{tabular}{lccr}
\hline \hline Koefisien teknis & PO & Peranakan Simmental & Peranakan Limousine \\
\hline Calving interval & $17,78 \pm 1,40 \mathrm{bln}$ & $16,92 \pm 1,44 \mathrm{bln}$ & $16,24 \pm 1,44 \mathrm{bln}$ \\
Penjualan pedet & $9,76 \pm 4,91 \mathrm{bln}$ & $7,20 \pm 4,00 \mathrm{bln}$ & $7,91 \pm 5,36 \mathrm{bln}$ \\
\hline
\end{tabular}

Sumber : Data primer terolah, 2007

\section{Aspek Finansial Usahatani Pembibitan Sapi Potong}

\section{Investasi Usahatani Pembibitan Sapi Potong}

Untuk mengetahui lebih jelas
besarnya masing-masing komponen

investasi berdasarkan jenis sapi maka disajikan Tabel 3. Pada Tabel 3 terlihat bahwa biaya investasi terbesar adalah jenis sapi Peranakan Simmental. Besarnya nilai investasi tersebut disebabkan oleh tingginya biaya yang dikeluarkan peternak untuk bibit dan pembuatan kandang. Variasi material yang digunakan dalam pembuatan kandang 
antara peternak satu dengan peternak lain modal yang dimiliki peternak. berbeda-beda, tergantung kemampuan

Tabel 3. Investasi Usahatani Pembibitan 2 Ekor Induk Sapi per tahun di Kab. Sleman

\begin{tabular}{lrcc}
\hline \multirow{2}{*}{ Komponen } & \multicolumn{3}{c}{ Nilai investasi (Rp.) } \\
\cline { 2 - 4 } investasi & \multicolumn{1}{c}{ PO } & Peranakan Simmental & Peranakan Limousine \\
\hline Kandang & 1.555 .556 & 2.304 .000 & 1.220 .588 \\
Sapi bibit & 10.834 .556 & 13.045 .600 & 11.860 .235 \\
Peralatan & 387.582 & 289.320 & 300.354 \\
\hline \multicolumn{1}{c}{ Total } & 12.777 .694 & 15.638 .920 & 13.381 .177 \\
\hline
\end{tabular}

Sumber : Data primer terolah, 2007

Biaya Operasional Usahatani Pembibitan Sapi Potong

Biaya operasional pada usahatani pembibitan sapi potong ini diperhitungkan secara tunai dan nontunai yang dinilai berdasarkan opportunity costnya. Biaya operasional berdasarkan jenis sapi dapat dilihat pada Tabel 4.

Tabel 4. Biaya Operasional Usahatani Pembibitan 2 Ekor Induk per tahun di Kab. Sleman

\begin{tabular}{lrcr}
\hline \multirow{2}{*}{ Komponen } & \multicolumn{3}{c}{ Nilai biaya operasional (Rp) } \\
\cline { 2 - 4 } \multicolumn{1}{c}{ biaya operasional } & \multicolumn{1}{c}{ PO } & Peranakan Simmental & Peranakan Limousine \\
\hline Iuran & 2.667 & 3.320 & 3.000 \\
Sewa lahan pakan & 1.944 & 10.800 & 11.324 \\
Sewa lahan kandang & 29.639 & 38.120 & 28.824 \\
Konsentrat & 2.292 .200 & 2.252 .780 & 2.293 .059 \\
IB & 64.445 & 58.286 & 38.067 \\
Kesehatan & 8.444 & 5.920 & 6.118 \\
Obat-obatan & 19.194 & 16.020 & 16.735 \\
Tenaga kerja & 348.074 & 270.328 & 298.575 \\
Peralatan & 14.333 & 19.180 & 14.412 \\
\hline \multicolumn{1}{c}{ Total } & 2.780 .940 & 2.674 .754 & 2.710 .114
\end{tabular}

Sumber : Data primer terolah, 2007

Tabel 4 menunjukkan bahwa biaya operasional untuk sapi pembibitan tidak berbeda jauh untuk tiga jenis sapi yaitu berkisar Rp 2.674.754,00 sampai dengan Rp 2.780.940,00. Biaya operasional pada usahatani pembibitan sapi potong terbesar adalah terletak pada biaya pakan terutama konsentrat. Sesuai dengan pendapat Prawirokusumo (1990) bahwa biaya pakan biasanya terbesar dalam usaha peternakan yaitu berkisar antara 60 sampai $80 \%$ dari total biaya.

\section{Penerimaan Usahatani Pembibitan Sapi Potong}

Pada usahatani pembibitan sapi potong ini penerimaan peternak berasal dari penjualan pedet sebagai produk pokok dan pupuk kandang sebagai produk sampingan yang dihasilkan oleh peternak serta nilai induk afkir.

\section{Analisis BEP}

Analisis break even merupakan analisis yang menunjukkan banyaknya volume penjualan yang dapat menutup biaya operasionalnya. Hal ini berarti pada volume penjualan tersebut usahatani pembibitan sapi potong tidak mengalami rugi maupun laba (Wibisono, 1997). Untuk mengetahui lebih 
jelas mengenai besar nilai BEP pada usahatani pembibitan sapi potong dengan

penghitungan penjualan pedet maka disajikan Tabel 5.

Tabel 5. Nilai BEP Usahatani Pembibitan 2 Ekor Induk Sapi Potong

\begin{tabular}{lcccc}
\hline \multirow{2}{*}{ Uraian } & \multicolumn{4}{c}{ Jenis sapi } \\
\cline { 2 - 5 } & & PO & $\begin{array}{c}\text { Peranakan } \\
\text { Simmental }\end{array}$ & $\begin{array}{c}\text { Peranakan } \\
\text { Limousine }\end{array}$ \\
\hline Biaya tetap & $\mathrm{Rp} \mathrm{12.519.306,00}$ & $\mathrm{Rp} \mathrm{15.446.040,00}$ & $\mathrm{Rp} \mathrm{13.180.941,00}$ \\
Biaya variabel & $\mathrm{Rp} 2.780 .940,00$ & $\mathrm{Rp} 2.674 .754,00$ & $\mathrm{Rp} 2.710 .114,00$ \\
Penjualan & $\mathrm{Rp} 5.521 .429,00$ & $\mathrm{Rp} 6.743 .905,00$ & $\mathrm{Rp} 6.528 .711,00$ \\
\hline BEP (rupiah) & $\mathrm{Rp} \mathrm{25.223.401,00}$ & $\mathrm{Rp} \mathrm{25.599.104,00}$ & $\mathrm{Rp} \mathrm{22.535.649,00}$ \\
BEP (unit/ekor) & 9,14 & 7,59 & 6,90 \\
\hline
\end{tabular}

Sumber : Data primer terolah, 2007

Tabel 5 terlihat bahwa nilai BEP (unit/ekor) usahatani pembibitan sapi PL lebih rendah dibandingkan sapi PO dan PS. Nilai BEP berdasarkan kondisi peternak pada sapi PS, PO dan PL berturut-turut sebesar 8, 9 dan 7 ekor induk. Hal ini berarti bahwa peternak akan memperoleh keuntungan setiap tahun apabila memelihara induk lebih dari 8 ekor untuk jenis Peranakan Simmental, 9 ekor untuk jenis PO dan 7 ekor untuk jenis Peranakan Limousine.

\section{KESIMPULAN}

Nilai BEP dengan penghitungan penjualan pedet berdasarkan kondisi peternak pada sapi PS, PO dan PL berturutturut sebesar 8, 9 dan 7 ekor induk. Hal ini berarti bahwa peternak akan memperoleh keuntungan setiap tahun apabila memelihara induk lebih dari 8 ekor untuk jenis sapi PS, 9 ekor untuk jenis sapi PO dan di atas 7 ekor untuk jenis sapi PL.

\section{DAFTAR PUSTAKA}

Ditjen Peternakan. 2006. Statistik Peternakan. Direktorat Jenderal Peternakan. Departemen Pertanian RI, Jakarta.

Mosher, A.T. 1987. Menggerakkan dan Membangun Pertanian, SyaratSyarat Pokok Pembangunan dan Modernisasi. CV Yasaguna, Jakarta.

Pasaribu, A.M. 2005. Perencanaan dan Evaluasi Proyek Perikanan (Pengantar). Cetakan I. Hasanuddin University Press, Makassar.

Prawirokusumo, S. 1990. Ilmu Usaha Tani. Edisi I. BPFE, Yogyakarta.

Sigit, S. 2002. Analisa Break Even Rancangan Linier Secara Ringkas dan Praktis. Cetakan ke-9. BPFE, Yogyakarta.

Soegiharto, S. 2004. Potret Tenaga Kerja di Sektor Pertanian. Kapus Litbang Ketransmigrasian-Balitfo, Jakarta.

Sugiyono. 2006. Metode Penelitian Bisnis. Cetakan 9. CV Alfabeta. Bandung. Susieni, A. 2003. Studi Kelayakan Bisnis. Cetakan 2. Penerbit Andi, Yogyakarta. 